\title{
Review
}

Obesity and Metabolic Syndrome

Diabetes Metab J 2012;36:181-189

http://dx.doi.org/10.4093/dmj.2012.36.3.181

pISSN 2233-6079 • eISSN 2233-6087

DIABETES \& METABOLISM JOURNAL

\section{Leptin in Relation to the Lipodystrophy-Associated Metabolic Syndrome}

\author{
Christos S. Mantzoros ${ }^{1,2}$ \\ ${ }^{1}$ Division of Endocrinology, Diabetes, and Metabolism, Beth Israel Deaconess Medical Center, \\ ${ }^{2}$ Section of Endocrinology, Boston VA Healthcare System, Harvard Medical School, Boston, MA, USA
}

Leptin, an adipocyte-secreted hormone, regulates energy homeostasis as well as reproductive, neuroendocrine, immune and metabolic functions. Subjects with decreased amounts of fat in their adipose tissue, i.e., lipoatrophy, have low leptin levels. In the context of open-label, uncontrolled studies leptin administration, in physiological replacement doses, has been shown to have metabolically salutary effects in the rare patients with the syndrome of congenital lipodystrophy accompanied by leptin deficiency. Much more patients with lipodystrophy suffer from lipodystrophy and the metabolic syndrome associated with the use of highly active antiretroviral therapy. In this so called highly active antiretroviral therapy (HAART)-associated lipodystrophy and metabolic syndrome, patients demonstrate fat maldistribution with dyslipidemia, insulin resistance, and other metabolic complications. Leptin administration has been shown to decrease central fat mass and to improve fasting insulin/glucose levels and insulin sensitivity in human immunodeficiency virus-infected hypoleptinemic patients with HAART induced lipodystrophy and the metabolic syndrome. By contrast, the results of leptin treatment in leptin replete or hyperleptinemic obese individuals with glucose intolerance and diabetes mellitus have been minimal or null, presumably due to leptin tolerance or resistance that impairs leptin action. In this review, we present the emerging clinical applications and potential therapeutic uses of leptin in humans with lipodystrophy and the metabolic syndrome.

Keywords: Antiretroviral therapy, highly active; Glucose metabolism; HIV; Leptin; Lipodystrophy

\section{INTRODUCTION}

Leptin plays a crucial role in the regulation of energy homeostasis, insulin action and lipid metabolism [1]. As a hormone secreted by adipocytes in quantities which mainly reflect fat mass and secondarily acute energy deprivation as well as other factors, leptin serves as an important signal of body energy stores. Leptin deficiency in mice and/or in humans is associated with neuroendocrine and metabolic [1,2] abnormalities $[3,4]$, including insulin resistance and diabetes. All these abnormalities are corrected by exogenous leptin administration $[1,2,5,6]$, suggesting that leptin plays a role in glucose homeostasis and possibly in the pathogenesis of other obesity-related metabolic complications.

Interestingly, leptin-induced normalization of hyperglycemia and hyperinsulinemia in $o b / o b$ mice is observed even before any alteration in body weight takes place, suggesting that leptin's effects on glucose homeostasis are, in part, independent of its weight-reducing effects $[5,6]$. Similar to $o b / o b$ mice, other mouse models of obesity and leptin resistance or tolerance [7-9] have abnormalities reminiscent of leptin deficiency due to subnormal leptin action $[7,10,11]$. The importance of leptin is also evident in human physiology [3,4,7-18]. Leptin administration has been demonstrated to successfully treat obesity and its complications in individuals with congenital leptin deficiency, and thus leptin is available on a compassionate basis
Corresponding author: Christos S. Mantzoros

Division of Endocrinology, Diabetes, and Metabolism, Beth Israel Deaconess

Medical Center, Harvard Medical School, 330 Brookline Avenue FD 875, Boston, MA 02215, USA

E-mail: cmantzor@bidmc.harvard.edu
This is an Open Access article distributed under the terms of the Creative Commons Attribution Non-Commercial License (http://creativecommons.org/licenses/by-nc/3.0/) which permits unrestricted non-commercial use, distribution, and reproduction in any medium, provided the original work is properly cited. 
for these patients [5-7].

Recent evidence has suggested that leptin is effective in correcting neuroendocrine abnormalities and insulin resistance in patients with human immunodeficiency virus (HIV)-associated lipodystrophy $[11-13,19]$ as well as congenital lipodystrophy [8-10].

\section{CONGENITAL LIPODYSTROPHY}

Lipodystrophy is a group of clinically heterogeneous acquired or inherited disorders characterized by complete or partial absence of subcutaneous fat that can occur in conjunction with the pathological accumulation of adipose tissue in other distinct regions of the body $[10,20]$. Though inherited lipodystrophies are exceedingly rare, acquired lipodystrophies (especially resulting HIV infection and its treatment) are more common. Interestingly, lipodystrophic patients exhibit insulin resistance, hyperglycemia, dyslipidemia, and hepatic steatosis [21]. The severity of these metabolic abnormalities typically correlates with the degree of adipose tissue loss (see below).

In humans, congenital lipodystrophy syndromes are rare; there have been less than a few hundred cases described in the literature and it is expected that there are less than 1,000 people suffering from this condition in North America [22,23]. The lipodystrophies are associated with partial or total leptin deficiency [24]. Leptin replacement dramatically improved dyslipidemia and insulin sensitivity and reduced $\mathrm{HbA1c}$ levels and intrahepatic fat content in various types of human lipodystrophy [25-32]. Fasting blood glucose and HbA1c levels decreased markedly even in patients who are not fully responsive to other antihyperglycemic medications or high doses of insulin [28]. Hyperglycemic-euglycemic clamps in three patients with lipoatrophic diabetes have shown remarkable improvement in insulin sensitivity after leptin treatment [26]. This beneficial effect was seen with respect to both hepatic insulin sensitivity and whole-body insulin sensitivity. In conjunction with this, there was an $86 \%$ reduction in intrahepatic triglyceride content and a 33\% reduction in muscle triglyceride content [26]. In a recently published open-label, uncontrolled prospective study in 48 patients with various acquired and inherited forms of lipodystrophy [30], leptin replacement effectively decreased serum triacylglycerol concentrations by $59 \%$ and HbA1c levels by 1.5 percentage-points within 1 year. The benefits of leptin replacement were sustained for up to 8 years of follow-up in the context of open label studies [30]. Oral and Chan [32] collected several small, non-randomized, openlabel trials in a composite study reporting on a total of more than 100 patients with severe lipodystrophy. These studies have found improvement in several metabolic parameters, including glycemic control, insulin sensitivity, plasma triglycerides, caloric intake, liver volume and lipid content, and intramyocellular lipid content, with leptin treatment [33]. In summary, all these studies have demonstrated that leptin could be an effective regimen that can be used to overcome the metabolic abnormalities characteristic of lipodystrophy, and have provided the rationale for metreleptin treatment in these patients. However, there are several issues that deserve serious consideration. Published reports are all open-label and uncontrolled; thus, a placebo-controlled trial is warranted to fully determine efficacy and safety. Given the small number of patients and the lack of firm diagnostic criteria are hurdles to perform a trial of parallel design, a cross over design should be more appropriate in this case [23]. Future trials should also allow a comparison with the current standard of care. Importantly, the side effect profile of leptin has not yet been fully characterized; although deterioration of renal function, lymphomas, and the development of antibodies to leptin have all been reported $[32,34,35]$, it remains unknown whether these side effects are due to therapy versus the disease process per se. The optimal treatment regimen including dose and frequency has also not been determined. Nevertheless, metreleptin is available from the manufacturer for the treatment of leptin as part of the expanded access program, and an application for approval for this indication is under review by the U.S. Food and Drug Administration (FDA).

\section{HIGHLY ACTIVE ANTIRETROVIRAL THERAPY (HAART)-ASSOCIATED LIPODYSTROPHY}

More than 40 million people worldwide are currently living with HIV, including more than eight million individuals in Southeast Asia [36]. The widespread use of HAART has dramatically altered both the morbidity, mortality and long term outcomes but the prolonged life expectancy of patients receiving HAART, has also been associated with a dramatic increase of the incidence and prevalence of adverse effects and toxicity [37]. A frequently observed adverse effect of HAART involves metabolic abnormalities associated with lipodystrophy [38], i.e., the HAART-associated lipodystrophy syndrome (HALS). 


\section{HALS}

Abnormal fat distribution, called the HALS, is associated with dyslipidemia, insulin resistance, and other metabolic complications $[38,39]$. The prevalence of these adverse effects depends on the HAART regimen and increases with use over time [40,41]. Patients may experience lipoatrophy, lipohypertrophy, or clinical features of both [42]. Lipoatrophy occurs in approximately $20 \%$ of patients on HAART in our experience and is typically characterized by a loss of subcutaneous adipose tissue in the face and extremities [37,41]. Other patients with HAART induced metabolic syndrome may have lipoatrophy in the extremeties in the context of stable or increased visceral adipose tissue and a normal or even increased waist:hip ratio [43]. At the other end of the spectrum, lipohypertrophy is characterized by generalized or central fat accumulation [44]. The majority of the patients on HAART display a combination of lipoatrophy and lipohypertrophy, called mixed lipodystrophy, which is also closely associated with metabolic abnormalities [45].

The pathogenesis of HAART associated lipodystrophy and the metabolic syndrome is thought to be multifactorial [40]. This process involves impairment of both adipocyte differentiation and ectopic fat deposition either intra-abdominally or in areas other than the adipose tissue, such as liver, muscle, etc. [46]. This is associated with increased lipolysis [47], which in turn creates a lipotoxic environment with elevated serum free fatty acids (FFAs) and subsequent intracellular accumulation of FFAs. Ectopic deposition of FFAs in visceral adipose tissue, skeletal muscle, liver, and pancreas exacerbates dyslipidemia and insulin resistance [48] which eventually leads to metabolic syndrome and diabetes in susceptible individuals $[49,50]$.

Among HAART, protease inhibitors and nucleoside reverse transcriptase inhibitors (NRTIs) have been shown to affect insulin resistance and glucose metabolism by seemingly different pathways [51]. Protease inhibitors have been suggested to stimulate lipolysis while inhibiting adipocyte differentiation and lipogenesis by interfering with peroxisome proliferatoractivated receptor-gamma (PPAR- $\gamma$ ) [40]. NRTIs may cause lipoatrophy secondary to mitochondrial injury within adipocytes [40], and their toxic metabolic effects appear synergistic with protease inhibitors [52]. Non-nucleoside reverse transcriptase inhibitors have also been implicated in this disease process; however, the effects of this drug class are still being investigated [53]. Viral proteins and mechanisms related to HIV-1 infection have also been suggested to influence adipose tissue distribution directly [54].

\section{THE ROLE OF ADIPOKINES IN HALS}

We and others have shown that levels of adipokines leptin and adiponectin are decreased in patients with HALS, suggesting that they may play a fundamental role in the metabolic abnormalities observed in lipodystrophy $[44,55,56]$, replacement of adipokines could be a physiological approach to the therapy of the syndrome and may provide considerable therapeutic value for HALS patients.

\section{Adiponectin}

Levels of the beneficial, adipocyte secreted hormone-insulin sensitizer adiponectin are low in obesity, diabetes, and subsets of individuals with lipodystrophy accompanied by central lipohypertrophy, including many patients with HALS [24,57-59]. Low adiponectin levels are associated with insulin resistance, hypertriglyceridemia, and adipose tissue redistribution in HIV patients receiving HAART [55]. Although adiponectin is not currently available for treatment in humans, studies in mice have demonstrated improved insulin sensitivity, dyslipidemia, and weight loss [17]. Further research is needed to determine the potential for adiponectin replacement, or the use of adiponectin receptor analogues, in humans and the extent of its effects, specifically in HALS. In the meantime, we have shown that medications that increase adiponectin levels, such as pioglitazone, improve components of HALS (see below).

\section{Leptin}

Leptin is synthesized and secreted by adipocytes and is involved in energy homeostasis, while generally reflecting the amount of energy stores within the body [17]. Leptin acts centrally to promote satiety and decreased food intake [13], while also acting peripherally to decrease gluconeogenesis in the liver and adipose tissue and increase glucose utilization by skeletal muscle through pathways overlapping with insulin [60].

A significant subgroup of patients with lipodystrophy exhibit low leptin levels, including patients with HALS [44]. In studies in congenital and non-HIV related acquired lipodystrophy, physiological replacement doses of leptin (0.04 to 0.08 $\mathrm{mg} / \mathrm{kg}$ daily) have resulted in significant weight loss, improved insulin sensitivity and glucose tolerance, and reduced hemoglobin Alc levels [25,26,28]. 
Similar results have been demonstrated in studies of patients with HALS. We have demonstrated that in a randomized, placebo-controlled, double-blinded crossover study in seven hypoleptinemic men with HALS, physiologic metreleptin replacement doses administered for 2 months improved metabolic parameters in these patients. Leptin treatment was associated with a $14.6 \%$ adjusted decrease in central fat mass and significant improvements in fasting glucose and insulin levels, insulin resistance and high density lipoprotein cholesterol (HDLC) levels [61].

A similar independent study of longer duration confirmed these results, demonstrating a $32 \%$ decrease in visceral fat, improved lipid profiles, and increased hepatic insulin sensitivity with metreleptin treatment [62]. The improvements in central fat mass and lipid profiles observed in these studies [61,62] were comparable to those reported with metformin and thiazolidinediones in HALS patients [63-65], and provide an advantage over growth hormone $(\mathrm{GH})$ replacement because leptin has not been seen to cause glucose intolerance [66].

Recombinant metreleptin therapy was well-tolerated in both studies, and their results suggest that the benefits of leptin replacement are sustained throughout treatment in patients with HALS $[61,62]$. Patients with various forms of congenital, nonHIV related, lipodystrophy followed for up to 8 years have also demonstrated sustained benefit with uninterrupted metreleptin treatment [30].

\section{FUTURE DIRECTIONS OF THERAPY}

As each therapy discussed has shown some benefit to HALS patients, combination therapies are currently being studied for potential use in these patients. In a 3-month pilot study of leptin treatment in addition to pioglitazone in adult men with HALS, we observed improved insulin sensitivity and postprandial glucose levels in comparison to pioglitazone treatment alone [67]. Improvements in body fat mass and distribution were not observed during the short duration of this trial; however, it is unclear if leptin's known fat-reducing effects $[61,62]$ were affected by the coadministration of pioglitazone.

Leptin's effects on improving lipodystrophy have also been observed to act independently of the GH and insulin-like growth factor 1 (IGF-1) system [68]. As treatment with recombinant IGF-1/IGF-binding protein-3 [69] or GH and GH releasing hormone (GHRH) analogs [70-72] have demonstrated decreases in visceral fat and improvement of lipodystrophy, a combination therapy with leptin could potentially have additive metabolic effects $[68,73,74]$.

\section{TREATMENT OF IMPAIRED GLUCOSE TOLERANCE IN LIPODYSTROPHY}

A variety of treatment options have been studied to control the effects of HALS, but widely accepted guidelines have not yet been established. The target of ideal treatment for HALS would aim to treat both the metabolic disturbances and pathological changes in adipose tissue distribution. Two of the most commonly used medications to treat the associated glucose intolerance include metformin and thiazolidinediones. Although metformin is recommended for treatment of type 2 diabetes mellitus it is not FDA-approved for lipodystrophy syndromes. Metformin treatment improves insulin sensitivity by decreasing hepatic gluconeogenesis and enhancing peripheral glucose utilization and thus has been shown in small, randomized controlled trials to significantly reduce weight and insulin resistance in patients with HALS [75]. However, metformin is contraindicated in states that may predispose to lactic acidosis, including states of impaired renal function, may worsen peripheral adipose tissue loss, and thus has been used with extreme caution in patients with lipoatrophy [65]. Thiazolidinediones are likewise not FDA-approved for use in lipodystrophy. They bind and activate the PPAR- $\gamma$ nuclear transcription factor, which regulates adipocyte differentiation and promotes production of adiponectin [76]. We have shown that treatment with the only currently FDA approved TZD, pioglitazone, increases adiponectin and improves lipid profiles and insulin resistance over a 12-month period by decreasing triglyceride levels and increasing HDL-C levels in patients with HALS [77].

\section{CONCLUSIONS}

Leptin administration, in replacement doses, has been shown in the context of long term, uncontrolled studies, to be effective in improving the metabolic and neuroendocrine abnormalities in subjects with congenital lipodystrophy. Thus, an application by Amylin Inc. has been submitted to the FDA for approval of leptin in replacement doses for the treatment of congenital lipodystrophy. It remains to be seen whether leptin will be approved for this indication in the absence of well controlled, randomized studies that could allow a more precise 
assessment of efficacy and side effects. In the meantime, leptin is available through an expanded access program for subjects with congenital lipodystrophy and leptin deficiency.

As the global epidemic of HIV and associated comorbidities continues to have a striking impact, particularly in Southeast Asia, HALS is much more prevalent than congenital lipodystrophy and still represents a significant therapeutic challenge. Much more work is needed to better understand the pathogenesis of HALS and to evaluate, in the context of large randomized phase III clinical trials, novel therapy regimens such as adipokines, including leptin administration. Additional well-designed, placebo-controlled clinical trials of sufficient power and duration are needed to further evaluate mechanisms of action of leptin alone or in combination, dosing intervals and treatment duration for leptin treatments, as well as optimal drug combinations for treatment of lipodystrophy $[46,49,50]$.

In contrast to findings in leptin deficient lipodystrophic subjects, in subjects with garden-variety obesity or diabetes (who have high concentrations of not only insulin but also leptin presumably due to leptin tolerance or resistance) [78,79], treatment with additional exogenous leptin has not been associated with significant weight loss or reduction in metabolic complications $[20,80,81]$. This suggests that there is leptin tolerance or resistance in these subjects $[82,83]$. Hence, although great progress has been made in understanding the role of leptin in many physiological systems, much research is currently being directed toward elucidating the mechanisms and pathophysiology of leptin's effects or resistance to leptin's effects on glucose metabolism in subjects with excess adipose tissue and thus leptin excess.

\section{CONFLICTS OF INTEREST}

No potential conflict of interest relevant to this article was reported.

\section{REFERENCES}

1. Kershaw EE, Flier JS. Adipose tissue as an endocrine organ. J Clin Endocrinol Metab 2004;89:2548-56.

2. Pelleymounter MA, Cullen MJ, Baker MB, Hecht R, Winters D, Boone T, Collins F. Effects of the obese gene product on body weight regulation in ob/ob mice. Science 1995;269:540-3.

3. Dardeno TA, Chou SH, Moon HS, Chamberland JP, Fiorenza CG, Mantzoros CS. Leptin in human physiology and thera- peutics. Front Neuroendocrinol 2010;31:377-93.

4. Chan JL, Mantzoros CS. Role of leptin in energy-deprivation states: normal human physiology and clinical implications for hypothalamic amenorrhoea and anorexia nervosa. Lancet 2005; 366:74-85.

5. Halaas JL, Gajiwala KS, Maffei M, Cohen SL, Chait BT, Rabinowitz D, Lallone RL, Burley SK, Friedman JM. Weight-reducing effects of the plasma protein encoded by the obese gene. Science 1995;269:543-6.

6. Campfield LA, Smith FJ, Guisez Y, Devos R, Burn P. Recombinant mouse $\mathrm{OB}$ protein: evidence for a peripheral signal linking adiposity and central neural networks. Science 1995;269: 546-9.

7. Chan JL, Moschos SJ, Bullen J, Heist K, Li X, Kim YB, Kahn BB, Mantzoros CS. Recombinant methionyl human leptin administration activates signal transducer and activator of transcription 3 signaling in peripheral blood mononuclear cells in vivo and regulates soluble tumor necrosis factor-alpha receptor levels in humans with relative leptin deficiency. J Clin Endocrinol Metab 2005;90:1625-31.

8. Houseknecht KL, Mantzoros CS, Kuliawat R, Hadro E, Flier JS, Kahn BB. Evidence for leptin binding to proteins in serum of rodents and humans: modulation with obesity. Diabetes 1996;45:1638-43.

9. Pierroz DD, Ziotopoulou M, Ungsunan L, Moschos S, Flier IS, Mantzoros CS. Effects of acute and chronic administration of the melanocortin agonist MTII in mice with diet-induced obesity. Diabetes 2002;51:1337-45.

10. Bluher S, Mantzoros CS. Leptin in humans: lessons from translational research. Am J Clin Nutr 2009;89:991S-7S.

11. Brennan AM, Mantzoros CS. Drug Insight: the role of leptin in human physiology and pathophysiology: emerging clinical applications. Nat Clin Pract Endocrinol Metab 2006;2:318-27.

12. Brinkoetter M, Magkos F, Vamvini M, Mantzoros CS. Leptin treatment reduces body fat but does not affect lean body mass or the myostatin-follistatin-activin axis in lean hypoleptinemic women. Am J Physiol Endocrinol Metab 2011;301:E99-104.

13. Kelesidis T, Kelesidis I, Chou S, Mantzoros CS. Narrative review: the role of leptin in human physiology: emerging clinical applications. Ann Intern Med 2010;152:93-100.

14. Bluher S, Mantzoros CS. The role of leptin in regulating neuroendocrine function in humans. J Nutr 2004;134:2469S-74S.

15. Chan JL, Bluher S, Yiannakouris N, Suchard MA, Kratzsch J, Mantzoros CS. Regulation of circulating soluble leptin receptor levels by gender, adiposity, sex steroids, and leptin: obser- 
vational and interventional studies in humans. Diabetes 2002; 51:2105-12.

16. Chan JL, Mantzoros CS. Leptin and the hypothalamic-pituitary regulation of the gonadotropin-gonadal axis. Pituitary 2001;4: 87-92.

17. Mantzoros CS. Role of leptin in reproduction. Ann N Y Acad Sci 2000;900:174-83.

18. Mantzoros CS. The role of leptin in human obesity and disease: a review of current evidence. Ann Intern Med 1999;130:671-80.

19. Fiorenza CG, Chou SH, Mantzoros CS. Lipodystrophy: pathophysiology and advances in treatment. Nat Rev Endocrinol 2011;7:137-50.

20. Moon HS, Chamberland JP, Diakopoulos KN, Fiorenza CG, Ziemke F, Schneider B, Mantzoros CS. Leptin and amylin act in an additive manner to activate overlapping signaling pathways in peripheral tissues: in vitro and ex vivo studies in humans. Diabetes Care 2011;34:132-8.

21. Garg A, Agarwal AK. Lipodystrophies: disorders of adipose tissue biology. Biochim Biophys Acta 2009;1791:507-13.

22. Chan JL, Oral EA. Clinical classification and treatment of congenital and acquired lipodystrophy. Endocr Pract 2010;16:31023.

23. Mantzoros CS. W(h)ither metreleptin for lipodystrophy and the metabolic syndrome? Endocr Pract 2010:1-18.

24. Haque WA, Shimomura I, Matsuzawa Y, Garg A. Serum adiponectin and leptin levels in patients with lipodystrophies. J Clin Endocrinol Metab 2002;87:2395.

25. Oral EA, Simha V, Ruiz E, Andewelt A, Premkumar A, Snell P, Wagner AJ, DePaoli AM, Reitman ML, Taylor SI, Gorden P, Garg A. Leptin-replacement therapy for lipodystrophy. N Engl J Med 2002;346:570-8.

26. Petersen KF, Oral EA, Dufour S, Befroy D, Ariyan C, Yu C, Cline GW, DePaoli AM, Taylor SI, Gorden P, Shulman GI. Leptin reverses insulin resistance and hepatic steatosis in patients with severe lipodystrophy. J Clin Invest 2002;109:1345-50.

27. Ebihara K, Masuzaki H, Nakao K. Long-term leptin-replacement therapy for lipoatrophic diabetes. N Engl J Med 2004; 351:615-6.

28. Javor ED, Cochran EK, Musso C, Young JR, Depaoli AM, Gorden P. Long-term efficacy of leptin replacement in patients with generalized lipodystrophy. Diabetes 2005;54:1994-2002.

29. Javor ED, Ghany MG, Cochran EK, Oral EA, DePaoli AM, Premkumar A, Kleiner DE, Gorden P. Leptin reverses nonalcoholic steatohepatitis in patients with severe lipodystrophy. Hepatology 2005;41:753-60.
30. Chong AY, Lupsa BC, Cochran EK, Gorden P. Efficacy of leptin therapy in the different forms of human lipodystrophy. Diabetologia 2010;53:27-35.

31. Ebihara K, Kusakabe T, Hirata M, Masuzaki H, Miyanaga F, Kobayashi N, Tanaka T, Chusho H, Miyazawa T, Hayashi T, Hosoda K, Ogawa Y, DePaoli AM, Fukushima M, Nakao K. Efficacy and safety of leptin-replacement therapy and possible mechanisms of leptin actions in patients with generalized lipodystrophy. J Clin Endocrinol Metab 2007;92:532-41.

32. Oral EA, Chan JL. Rationale for leptin-replacement therapy for severe lipodystrophy. Endocr Pract 2010;16:324-33.

33. Chan JL, Lutz K, Cochran E, Huang W, Peters Y, Weyer C, Gorden P. Clinical effects of long-term metreleptin treatment in patients with lipodystrophy. Endocr Pract 2011;17:922-32.

34. Savage DB, O'Rahilly S. Leptin therapy in lipodystrophy. Diabetologia 2010;53:7-9.

35. Javor ED, Moran SA, Young JR, Cochran EK, DePaoli AM, Oral EA, Turman MA, Blackett PR, Savage DB, O'Rahilly S, Balow JE, Gorden P. Proteinuric nephropathy in acquired and congenital generalized lipodystrophy: baseline characteristics and course during recombinant leptin therapy. J Clin Endocrinol Metab 2004;89:3199-207.

36. McCutchan FE. Global epidemiology of HIV. J Med Virol 2006; 78 Suppl 1:S7-12.

37. Tsiodras S, Mantzoros C, Hammer S, Samore M. Effects of protease inhibitors on hyperglycemia, hyperlipidemia, and lipodystrophy: a 5-year cohort study. Arch Intern Med 2000;160: 2050-6.

38. Dybul M, Fauci AS, Bartlett JG, Kaplan JE, Pau AK; Panel on Clinical Practices for Treatment of HIV. Guidelines for using antiretroviral agents among HIV-infected adults and adolescents. Ann Intern Med 2002;137(5 Pt 2):381-433.

39. Dimock D, Thomas V, Cushing A, Purdy JB, Worrell C, Kopp JB, Hazra R, Hadigan C. Longitudinal assessment of metabolic abnormalities in adolescents and young adults with HIV-infection acquired perinatally or in early childhood. Metabolism 2011;60:874-80.

40. Grinspoon S, Carr A. Cardiovascular risk and body-fat abnormalities in HIV-infected adults. N Engl J Med 2005;352:48-62.

41. Leow MK, Addy CL, Mantzoros CS. Clinical review 159: Human immunodeficiency virus/highly active antiretroviral therapy-associated metabolic syndrome: clinical presentation, pathophysiology, and therapeutic strategies. J Clin Endocrinol Metab 2003;88:1961-76.

42. Shlay JC, Sharma S, Peng G, Gibert CL, Grunfeld C; Terry 
Beirn Community Programs for Clinical Research on AIDS (CPCRA); International Network for Strategic Initiatives in Global HIV Trials (INSIGHT). The effect of individual antiretroviral drugs on body composition in HIV-infected persons initiating highly active antiretroviral therapy. J Acquir Immune Defic Syndr 2009;51:298-304.

43. Estrada V, Serrano-Rios M, Martinez Larrad MT, Villar NG, Gonzalez Lopez A, Tellez MJ, Fernandez C. Leptin and adipose tissue maldistribution in HIV-infected male patients with predominant fat loss treated with antiretroviral therapy. J Acquir Immune Defic Syndr 2002;29:32-40.

44. Nagy GS, Tsiodras S, Martin LD, Avihingsanon A, Gavrila A, Hsu WC, Karchmer AW, Mantzoros CS. Human immunodeficiency virus type 1-related lipoatrophy and lipohypertrophy are associated with serum concentrations of leptin. Clin Infect Dis 2003;36:795-802.

45. Saves M, Raffi F, Capeau J, Rozenbaum W, Ragnaud JM, Perronne C, Basdevant A, Leport C, Chene G; Antiproteases Cohorte (APROCO) Study Group. Factors related to lipodystrophy and metabolic alterations in patients with human immunodeficiency virus infection receiving highly active antiretroviral therapy. Clin Infect Dis 2002;34:1396-405.

46. Mantzoros CS, Magkos F, Brinkoetter M, Sienkiewicz E, Dardeno TA, Kim SY, Hamnvik OP, Koniaris A. Leptin in human physiology and pathophysiology. Am J Physiol Endocrinol Metab 2011;301:E567-84.

47. Hadigan C, Borgonha S, Rabe J, Young V, Grinspoon S. Increased rates of lipolysis among human immunodeficiency virus-infected men receiving highly active antiretroviral therapy. Metabolism 2002;51:1143-7.

48. Villarroya F, Domingo P, Giralt M. Drug-induced lipotoxicity: lipodystrophy associated with HIV-1 infection and antiretroviral treatment. Biochim Biophys Acta 2010;1801:392-9.

49. Tsiodras S, Mantzoros C. Leptin and adiponectin in the HIV associated metabolic syndrome: physiologic and therapeutic implications. Am J Infect Dis 2006;2:141-52.

50. Magkos F, Mantzoros CS. Body fat redistribution and metabolic abnormalities in HIV-infected patients on highly active antiretroviral therapy: novel insights into pathophysiology and emerging opportunities for treatment. Metabolism 2011;60: 749-53.

51. van Vonderen MG, Blumer RM, Hassink EA, Sutinen J, Ackermans MT, van Agtmael MA, Yki-Jarvinen H, Danner SA, Serlie MJ, Sauerwein HP, Reiss P. Insulin sensitivity in multiple pathways is differently affected during zidovudine/lamivudine- containing compared with NRTI-sparing combination antiretroviral therapy. J Acquir Immune Defic Syndr 2010;53:186-93.

52. Roche R, Poizot-Martin I, Yazidi CM, Compe E, Gastaut JA, Torresani J, Planells R. Effects of antiretroviral drug combinations on the differentiation of adipocytes. AIDS 2002;16:13-20.

53. Haubrich RH, Riddler SA, DiRienzo AG, Komarow L, Powderly WG, Klingman K, Garren KW, Butcher DL, Rooney JF, Haas DW, Mellors JW, Havlir DV; AIDS Clinical Trials Group (ACTG) A5142 Study Team. Metabolic outcomes in a randomized trial of nucleoside, nonnucleoside and protease inhibitor-sparing regimens for initial HIV treatment. AIDS 2009; 23:1109-18.

54. Shrivastav S, Kino T, Cunningham T, Ichijo T, Schubert U, Heinklein P, Chrousos GP, Kopp JB. Human immunodeficiency virus (HIV)-1 viral protein $\mathrm{R}$ suppresses transcriptional activity of peroxisome proliferator-activated receptor \{gamma\} and inhibits adipocyte differentiation: implications for HIVassociated lipodystrophy. Mol Endocrinol 2008;22:234-47.

55. Addy CL, Gavrila A, Tsiodras S, Brodovicz K, Karchmer AW, Mantzoros CS. Hypoadiponectinemia is associated with insulin resistance, hypertriglyceridemia, and fat redistribution in human immunodeficiency virus-infected patients treated with highly active antiretroviral therapy. J Clin Endocrinol Metab 2003;88:627-36.

56. Sweeney LL, Brennan AM, Mantzoros CS. The role of adipokines in relation to HIV lipodystrophy. AIDS 2007;21:895-904.

57. Kadowaki T, Yamauchi T. Adiponectin and adiponectin receptors. Endocr Rev 2005;26:439-51.

58. Tong Q, Sankale JL, Hadigan CM, Tan G, Rosenberg ES, Kanki PJ, Grinspoon SK, Hotamisligil GS. Regulation of adiponectin in human immunodeficiency virus-infected patients: relationship to body composition and metabolic indices. J Clin Endocrinol Metab 2003;88:1559-64.

59. Vigouroux C, Maachi M, Nguyen TH, Coussieu C, Gharakhanian S, Funahashi T, Matsuzawa Y, Shimomura I, Rozenbaum W, Capeau J, Bastard JP. Serum adipocytokines are related to lipodystrophy and metabolic disorders in HIV-infected men under antiretroviral therapy. AIDS 2003;17:1503-11.

60. Kim JK, Gavrilova O, Chen Y, Reitman ML, Shulman GI. Mechanism of insulin resistance in A-ZIP/F-1 fatless mice. J Biol Chem 2000;275:8456-60.

61. Lee JH, Chan JL, Sourlas E, Raptopoulos V, Mantzoros CS. Recombinant methionyl human leptin therapy in replacement doses improves insulin resistance and metabolic profile in patients with lipoatrophy and metabolic syndrome induced by the 
highly active antiretroviral therapy. J Clin Endocrinol Metab 2006;91:2605-11.

62. Mulligan K, Khatami H, Schwarz JM, Sakkas GK, DePaoli AM, Tai VW, Wen MJ, Lee GA, Grunfeld C, Schambelan M. The effects of recombinant human leptin on visceral fat, dyslipidemia, and insulin resistance in patients with human immunodeficiency virus-associated lipoatrophy and hypoleptinemia. J Clin Endocrinol Metab 2009;94:1137-44.

63. Hadigan C, Corcoran C, Basgoz N, Davis B, Sax P, Grinspoon S. Metformin in the treatment of HIV lipodystrophy syndrome: a randomized controlled trial. JAMA 2000;284:472-7.

64. Hadigan C, Yawetz S, Thomas A, Havers F, Sax PE, Grinspoon S. Metabolic effects of rosiglitazone in HIV lipodystrophy: a randomized, controlled trial. Ann Intern Med 2004;140:786-94.

65. Kohli R, Shevitz A, Gorbach S, Wanke C. A randomized placebo-controlled trial of metformin for the treatment of HIV lipodystrophy. HIV Med 2007;8:420-6.

66. Lo J, You SM, Canavan B, Liebau J, Beltrani G, Koutkia P, Hemphill L, Lee H, Grinspoon S. Low-dose physiological growth hormone in patients with HIV and abdominal fat accumulation: a randomized controlled trial. JAMA 2008;300:509-19.

67. Magkos F, Brennan A, Sweeney L, Kang ES, Doweiko J, Karchmer AW, Mantzoros CS. Leptin replacement improves postprandial glycemia and insulin sensitivity in human immunodeficiency virus-infected lipoatrophic men treated with pioglitazone: a pilot study. Metabolism 2011;60:1045-9.

68. Brennan AM, Lee JH, Tsiodras S, Chan JL, Doweiko J, Chimienti SN, Wadhwa SG, Karchmer AW, Mantzoros CS. r-metHuLeptin improves highly active antiretroviral therapy-induced lipoatrophy and the metabolic syndrome, but not through altering circulating IGF and IGF-binding protein levels: observational and interventional studies in humans. Eur J Endocrinol 2009;160:173-6.

69. Rao MN, Mulligan K, Tai V, Wen MJ, Dyachenko A, Weinberg M, Li X, Lang T, Grunfeld C, Schwarz JM, Schambelan M. Effects of insulin-like growth factor (IGF)-I/IGF-binding protein-3 treatment on glucose metabolism and fat distribution in human immunodeficiency virus-infected patients with abdominal obesity and insulin resistance. J Clin Endocrinol Metab 2010;95:4361-6.

70. Wanke C, Gerrior J, Kantaros J, Coakley E, Albrecht M. Recombinant human growth hormone improves the fat redistribution syndrome (lipodystrophy) in patients with HIV. AIDS 1999;13:2099-103.

71. Grunfeld C, Thompson M, Brown SJ, Richmond G, Lee D,
Muurahainen N, Kotler DP; Study 24380 Investigators Group. Recombinant human growth hormone to treat HIV-associated adipose redistribution syndrome: 12 week induction and 24week maintenance therapy. J Acquir Immune Defic Syndr 2007;45:286-97.

72. Bickel M, Zangos S, Jacobi V, Lutz T, Knecht G, Goebel F, Staszewski S, Klauke S. A randomized, open-label study to compare the effects of two different doses of recombinant human growth hormone on fat reduction and fasting metabolic parameters in HIV-1-infected patients with lipodystrophy. HIV Med 2006;7:397-403.

73. Mantzoros CS. Whither recombinant human leptin treatment for HIV-associated lipoatrophy and the metabolic syndrome? J Clin Endocrinol Metab 2009;94:1089-91.

74. Mantzoros CS, Moschos S, Avramopoulos I, Kaklamani V, Liolios A, Doulgerakis DE, Griveas I, Katsilambros N, Flier JS. Leptin concentrations in relation to body mass index and the tumor necrosis factor-alpha system in humans. J Clin Endocrinol Metab 1997;82:3408-13.

75. Hadigan C, Rabe J, Grinspoon S. Sustained benefits of metformin therapy on markers of cardiovascular risk in human immunodeficiency virus-infected patients with fat redistribution and insulin resistance. J Clin Endocrinol Metab 2002;87:4611-5.

76. Anghel SI, Bedu E, Vivier CD, Descombes P, Desvergne B, Wahli W. Adipose tissue integrity as a prerequisite for systemic energy balance: a critical role for peroxisome proliferator-activated receptor gamma. J Biol Chem 2007;282:29946-57.

77. Gavrila A, Hsu W, Tsiodras S, Doweiko J, Gautam S, Martin L, Moses AC, Karchmer AW, Mantzoros CS. Improvement in highly active antiretroviral therapy-induced metabolic syndrome by treatment with pioglitazone but not with fenofibrate: a $2 \times 2$ factorial, randomized, double-blinded, placebo-controlled trial. Clin Infect Dis 2005;40:745-9.

78. Mantzoros CS, Liolios AD, Tritos NA, Kaklamani VG, Doulgerakis DE, Griveas I, Moses AC, Flier IS. Circulating insulin concentrations, smoking, and alcohol intake are important independent predictors of leptin in young healthy men. Obes Res 1998;6:179-86.

79. Mantzoros CS, Cramer DW, Liberman RF, Barbieri RL. Predictive value of serum and follicular fluid leptin concentrations during assisted reproductive cycles in normal women and in women with the polycystic ovarian syndrome. Hum Reprod 2000;15:539-44.

80. Moon HS, Chamberland JP, Mantzoros CS. Amylin and leptin activate overlapping signalling pathways in an additive man- 
ner in mouse GT1-7 hypothalamic, CC muscle and AML12 liver cell lines. Diabetologia 2012;55:215-25.

81. Moon HS, Matarese G, Brennan AM, Chamberland JP, Liu X, Fiorenza CG, Mylvaganam GH, Abanni L, Carbone F, Williams CJ, De Paoli AM, Schneider BE, Mantzoros CS. Efficacy of metreleptin in obese patients with type 2 diabetes: cellular and molecular pathways underlying leptin tolerance. Diabetes 2011;60:1647-56.

82. Heymsfield SB, Greenberg AS, Fujioka K, Dixon RM, Kushner
R, Hunt T, Lubina JA, Patane J, Self B, Hunt P, McCamish M. Recombinant leptin for weight loss in obese and lean adults: a randomized, controlled, dose-escalation trial. JAMA 1999;282: 1568-75.

83. Considine RV, Sinha MK, Heiman ML, Kriauciunas A, Stephens TW, Nyce MR, Ohannesian JP, Marco CC, McKee LJ, Bauer TL, et al. Serum immunoreactive-leptin concentrations in normalweight and obese humans. N Engl J Med 1996;334:292-5. 